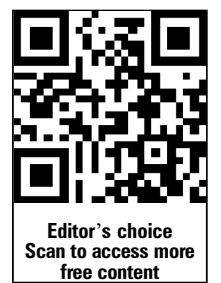

- Additional material is published online only. To view please visit the journal online (http://dx.doi.org/10.1136/ bjsports-2014-093502).

For numbered affiliations see end of article.

\section{Correspondence to} Dr Margo Mountjoy, Department of Family Medicine, Michael G. DeGroote School of Medicine, McMaster University Waterloo Regional Campus, 10-B Victoria Street South, Kitchener, Ontario, Canada N2G 1C5; mmsportdoc@mcmaster.ca

Accepted 3 February 2014

\title{
The IOC consensus statement: beyond the Female Athlete Triad-Relative Energy Deficiency in Sport (RED-S)
}

\author{
Margo Mountjoy, ${ }_{1}$ Jorunn Sundgot-Borgen, ${ }^{2}$ Louise Burke, ${ }^{3}$ Susan Carter, ${ }^{4}$ \\ Naama Constantini, ${ }^{5}$ Constance Lebrun, ${ }^{6}$ Nanna Meyer, ${ }^{7}$ Roberta Sherman, ${ }^{8}$ \\ Kathrin Steffen, ${ }^{2,9}$ Richard Budgett, ${ }^{9}$ Arne Ljungqvist ${ }^{9}$
}

\section{ABSTRACT}

Protecting the health of the athlete is a goal of the International Olympic Committee (IOC). The IOC convened an expert panel to update the 2005 IOC Consensus Statement on the Female Athlete Triad. This Consensus Statement replaces the previous and provides guidelines to guide risk assessment, treatment and return-to-play decisions. The IOC expert working group introduces a broader, more comprehensive term for the condition previously known as 'Female Athlete Triad'. The term 'Relative Energy Deficiency in Sport' (RED-S), points to the complexity involved and the fact that male athletes are also affected. The syndrome of RED-S refers to impaired physiological function including, but not limited to, metabolic rate, menstrual function, bone health, immunity, protein synthesis, cardiovascular health caused by relative energy deficiency. The cause of this syndrome is energy deficiency relative to the balance between dietary energy intake and energy expenditure required for health and activities of daily living, growth and sporting activities. Psychological consequences can either precede RED-S or be the result of RED-S. The clinical phenomenon is not a 'triad' of the three entities of energy availability, menstrual function and bone health, but rather a syndrome that affects many aspects of physiological function, health and athletic performance. This Consensus Statement also recommends practical clinical models for the management of affected athletes. The 'Sport Risk Assessment and Return to Play Model' categorises the syndrome into three groups and translates these classifications into clinical recommendations.

\section{INTRODUCTION}

Protecting the health of the athlete is one of the goals of the International Olympic Committee (IOC). ${ }^{1}$ The Olympic Movement Medical Code, which governs the actions of the IOC Medical Commission and sport organisations, also emphasises the importance of protecting the health of the athlete. $^{2}$ In 2005, the IOC published the Consensus Statement (Consensus Statement) and the IOC Position Stand (Position Stand) ${ }^{3}$ on the Female Athlete Triad. ${ }^{4}$ Based on scientific evidence published in the intervening period, this Consensus Statement serves to update and replace these documents and provide guidelines to the athlete health support team to guide risk assessment, treatment and return-to-play decisions for affected athletes.

\section{Relative energy deficiency in sport}

In the 2005 IOC Consensus Statement, ${ }^{4}$ the Female Athlete Triad (Triad) was defined as 'the combination of disordered eating (DE) and irregular menstrual cycles eventually leading to a decrease in endogenous oestrogen and other hormones, resulting in low bone mineral density'(BMD) based on the original scientific evidence of Drinkwater et al..$^{5}$ In 2007, following progress in scientific understanding, the American College of Sports Medicine redefined the Triad as a clinical entity that refers to the 'relationship between three interrelated components: energy availability (EA), menstrual function and bone health'. Added was an understanding of the pathophysiology describing the concept that over a period of time, the athlete moves along on a continuous spectrum ranging from the healthy athlete with optimal EA, regular menses and healthy bones to the opposite end of the spectrum characterised by amenorrhoea, low EA and osteoporosis. ${ }^{6}$

Since 2007, scientific evidence and clinical experience show that the aetiological factor underpinning the Triad is an energy deficiency relative to the balance between dietary energy intake (EI) and the energy expenditure required to support homoeostasis, health and the activities of daily living, growth and sporting activities. It is also evident that the clinical phenomenon is not a triad of three entities of EA, menstrual function and bone health, but rather a syndrome resulting from relative energy deficiency that affects many aspects of physiological function including metabolic rate, menstrual function, bone health, immunity, protein synthesis, cardiovascular and psychological health. In addition, it is evident that relative energy deficiency also affects men. Therefore, a new terminology is required to more accurately describe the clinical syndrome originally known as the Female Athlete Triad. Based on its interdisciplinary expertise, the IOC Consensus group introduces a more comprehensive, broader term for the overall syndrome, which includes what has so far been called the 'Female Athlete Triad': Relative Energy Deficiency in Sport (RED-S).

The syndrome of RED-S refers to impaired physiological function including, but not limited to, metabolic rate, menstrual function, bone health, immunity, protein synthesis, cardiovascular health caused by relative energy deficiency. 
The underlying problem of RED-S is an inadequacy of energy to support the range of body functions involved in optimal health and performance. EA is calculated as EI minus the energy cost of exercise relative to fat-free mass (FFM) and in healthy adults, a value of $45 \mathrm{kcal} / \mathrm{kg} \mathrm{FFM} /$ day equates energy balance. ${ }^{7}$ Low EA, which occurs with a reduction in EI and/or increased exercise load, causes adjustments to body systems to reduce energy expenditure, leading to disruption of an array of hormonal, metabolic and functional characteristics. ${ }^{7}$ DE underpins a large proportion of cases of low EA, but other situations, such as a mismanaged programme to quickly reduce body mass/fat or an inability to track EI with an extreme exercise commitment, may occur without such a psychological overlay. ${ }^{7}$

Although the literature on low EA has focused on female athletes, it has also been reported to occur in male athletes. ${ }^{8}$ Prevalence studies of low EA in male athletes have been few, however, low EA appears to occur among the same at risk sports as for female athletes: the weight sensitive sports in which leanness and/or weight are important due to their role in performance, appearance or requirement to meet a competition weight category. ${ }^{8}$

Although simple messages about optimal, tolerable and unsafe levels of EA have been provided ${ }^{9}$ there are some caveats in the science. First, the complex dose-response relationship between reduction in EA and the disruption of various hormones ${ }^{10}$ and bone formation markers ${ }^{11}$ vary in nature and thresholds. Therefore, the cost of any energy mismatch should be carefully considered before it is implemented. A second caveat is that it is now known that the resting metabolic rate in athletes of small body size is underestimated in the linear scaling of EA relative to LBM/FFM. ${ }^{12}$ Finally, findings from laboratory settings may not apply as cleanly to free-living athletes. Numerous studies in female athletes have failed to find clear thresholds or associations between field determinations of low EA and objective measures of energy conservation such as metabolic hormones ${ }^{13}$ and menstrual disturbances. ${ }^{14}$ It is possible that other factors seen in free-living populations such as psychological stress, greater variability in between-day and within-day energy deficiency or dietary characteristics interact with each other to alter the effects of low EA.

\section{Disordered eating}

The disordered eating (DE) continuum starts with appropriate eating and exercise behaviours, including healthy dieting and the occasional use of more extreme weight loss methods such as short-term restrictive diets $\left(<30 \mathrm{kcal} / \mathrm{kg} \mathrm{FFM} /\right.$ day). ${ }^{15}$ The continuum ends with clinical eating disorders (EDs), abnormal eating behaviours, distorted body image, weight fluctuations, medical complications and variable athletic performance. The Diagnostic and Statistical Manual of Mental Disorders (DSM-5) diagnostic classifications for EDs include anorexia nervosa, bulimia nervosa, binge ED and other specified and unspecified feeding or ED. ${ }^{16}$ These EDs have many features in common, and athletes frequently move among them. ${ }^{8}$ The pathogenesis of EDs is multifactorial with cultural, familial, individual and genetic/biochemical factors playing roles. ${ }^{17}$ In addition, factors specific to sport such as dieting to enhance performance, personality factors, pressure to lose weight, frequent weight cycling, early start of sport-specific training, overtraining, recurrent and non-healing injuries, inappropriate coaching behaviour and regulations in some sports have been suggested. ${ }^{8}$ The prevalence of DE is about $20 \%$ and $13 \%$ among adult and adolescent female elite athletes, and $8 \%$ and $3 \%$ in adult and adolescent male elite athletes, respectively. ${ }^{15} 18$ The prevalence differs significantly among sports. ${ }^{15}$

Hormonal and metabolic imbalance

Eumenorrhea is defined as regular cycles occurring at intervals between 21 and 35 days. In adolescents, the cycles range between 21 and 45 days. ${ }^{19}$ Primary amenorrhoea is defined as no menarche by age 15 years. ${ }^{20}$ Secondary amenorrhoea refers to an absence of three consecutive cycles post-menarche. Oligomenorrhea is defined as a cycle length greater than 45 days. Estimates of the prevalence of menstrual disorders in athletes vary widely. ${ }^{21}$ Secondary amenorrhoea prevalence is estimated in collegiate women from $2 \%$ to $5 \%$ and as high as $69 \%$ in dancers ${ }^{22}$ and $65 \%$ in long-distance runners. ${ }^{23}$ Primary amenorrhoea in collegiate athletes was found to be $7 \%$ overall, and was higher $(22 \%)$ in cheerleading, diving and gymnastics. ${ }^{24}$ Subtle menstrual dysfunction, such as very light bleeding, mildly extended menstrual interval and premenstrual and postmenstrual spotting may occur, and may be underestimated by routine screening. ${ }^{25}$

Abnormal levels of hormones, ${ }^{26} \mathrm{LH}$ pulsatility, inadequate body fat stores, low EA and exercise stress may be aetiological factors in menstrual disorders in athletes. Marked reduction in EA may disrupt the LH pulsatility by affecting the hypothalamic hormone gonadotropin-releasing hormone output ${ }^{27}$ which subsequently alters the menstrual cycle. This is known as Functional Hypothalamic Amenorrhea (FHA). Rapid or significant fat mass reduction, even over as short as a 1-month period, may compromise menstrual function. Low EA alters levels of metabolic hormones and substrates, for example, insulin, cortisol, growth hormone, insulin-like growth factor-I (IGF-I), 3,3,5-triiodothyronine, grehlin, leptin, peptide tyrosinetyrosine, glucose, fatty acids and ketones. ${ }^{28}$

\section{Health and performance consequences of RED-S}

RED-S can have serious implications for many body systems, resulting in short-term and long-term compromise of optimal health and performance. Athletes who suffer from long-term low EA may develop nutrient deficiencies (including anaemia), chronic fatigue and increased risk of infections and illnesses, all of which have the potential to harm health and performance. ${ }^{6}$ Physiological and medical complications involve the cardiovascular, gastrointestinal, endocrine, reproductive, skeletal, renal and central nervous systems. ${ }^{6}$ Psychological stress and/or depression can result in low EA and EDs and can also be a result of low EA. ${ }^{17}$ Research indicates that muscle protein synthesis is reduced even at EA of $30 \mathrm{kcal} / \mathrm{kg} \mathrm{FFM} / \mathrm{day}^{29}$ Low EA causes unfavourable lipid profiles and endothelial dysfunction, thereby increasing cardiovascular risk. $^{30}$ Hormonal and metabolic abnormalities caused by RED-S and carbohydrate deficiency can result in a reduction in glucose utilisation, mobilisation of fat stores, slowing of metabolic rate and a decreased production of growth hormone. ${ }^{31}$

Irregular or absent menses may have significant emotional impact creating anxiety and an altered perception of selfnormalcy. ${ }^{32}$ It may also confound conception, leading to unexpected pregnancy as well as inaccurate dating of pregnancy. Long-term reproductive repercussions of RED-S for women and men are unknown.

RED-S also has adverse health consequences for bone. Peak bone mass occurs around 19 years in women and 20.5 years in men. ${ }^{33}$ Oestrogen increases uptake of calcium into blood and deposition into bone, while progesterone facilitates the actions of oestrogen through multiple complex mechanisms. ${ }^{34}$ Even silent oestrogen/progesterone imbalance, as seen in subclinical 
ovulatory disturbances with low EA may produce negative changes in bone. ${ }^{35}$ In men and women, testosterone has anabolic effects on bone, stimulating osteoclasts and increasing bone formation and calcium absorption. ${ }^{36}$ Low-testosterone levels have been associated with low BMD in male athletes. ${ }^{37}$ Endogenous oestrogens and androgens have independent effects on bone development in both sexes. ${ }^{38} 39$ Increases in the stress hormones, catecholamines and cortisol, concomitant with low EA, have a negative effect. ${ }^{40}$ The bones of athletes with chronic amenorrhoea, benefit less from the osteogenic effects of exercise. ${ }^{41}$ Although low BMD was first attributed to hypoestrogenism of menstrual dysfunction, low EA is now recognised as an independent factor of poor bone health at all levels of energy deficiency due to decreased IgF-1 and bone formation markers levels. ${ }^{42}$ Bone loss in these athletes may be irreversible. ${ }^{43}$

Changes in bone structure lead to an increased risk of stress fractures. ${ }^{44}$ Dietary insufficiencies increase the risk of stress fractures in both sexes. ${ }^{45}{ }^{46}$ Additional risk factors include menstrual dysfunction, ${ }^{47}$ compulsive exercise, underlying poor bone health ${ }^{48} 49$ low body mass index, prior fracture ${ }^{50}$ and eating psychopathology. ${ }^{49-51}$ High-risk stress fractures (ie, femoral neck) occur in adolescent athletes with the RED-S, and can have serious long-term consequences ${ }^{52}{ }^{53}$ (figure 1). RED-S can also affect athletic performance. Functional impairments associated with low energy availability include a greater prevalence of viral illnesses,${ }^{55}$ injuries ${ }^{56}$ and most critically reduced responsiveness to training and subsequent performance. ${ }^{57}$ Further studies of performance effects of low energy availability are likely to provide significant incentive to change damaging behaviours. Such studies should confirm under which situations these effects occur (figure 2). In addition, some athletes with disordered eating/ eating disorders practise extreme weight control methods (fasting, vomiting, diuretic and laxative abuse) that have possible health and performance consequences such as dehydration and

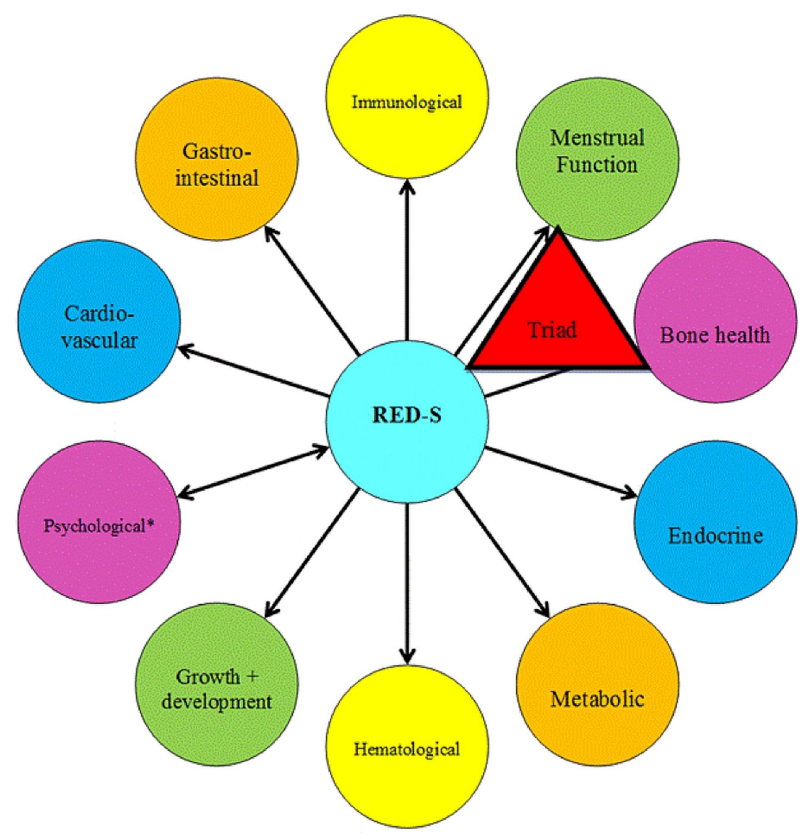

Figure 1 Health Consequences of Relative Energy Deficiency in Sport (RED-S) showing an expanded concept of the Female Athlete Triad to acknowledge a wider range of outcomes and the application to male athletes (*Psychological consequences can either precede RED-S or be the result of RED-S). Adapted from Constantini. ${ }^{5}$

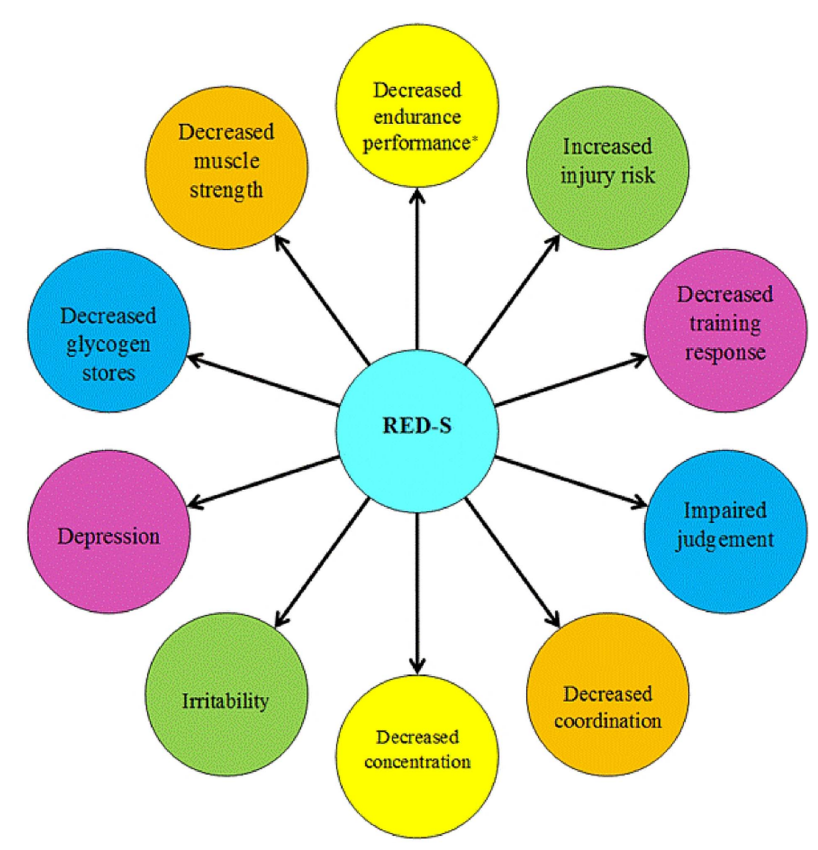

Figure 2 Potential Performance Effects of Relative Energy Deficiency in Sport ( ${ }^{*}$ Aerobic and anaerobic performance). Adapted from Constantini. ${ }^{54}$

electrolyte imbalances, and gastrointestinal problems, including esophagitis and oesophageal perforation from vomiting. Diuretics and some diet pills may contain WADA prohibited substances. ${ }^{58}$

\section{Male athletes}

Although there is a dearth of prevalence studies in low EA in male athletes, Vogt $e a^{59}$ showed that male cyclists had severely reduced EA of $8 \mathrm{kcal} / \mathrm{kg} / \mathrm{FFM} /$ day and Müller et al ${ }^{60}$ have reported high prevalence of underweight international level ski jumpers. Although male athletes are at lower risk for developing $\mathrm{DE} / \mathrm{ED}^{8} 1861$ the prevalence in elite male athletes is high in cycling $(50 \%),{ }^{62}$ gravitational $(24 \%)$ and weight class sports $(18 \%){ }^{15} \mathrm{DE} / \mathrm{EDs}$ in male jockeys are associated with low BMD. ${ }^{63}$ Even in the absence of DE/EDs, male endurance athletes in running ${ }^{37} 6465$ and in non-weight bearing sports such as cycling, ${ }^{66-69}$ are at high risk for low BMD. Low EA alters endocrine function ${ }^{11}$ and direct and indirect impacts on bone may occur in male athletes. ${ }^{70}$

\section{Athletes of non-caucasian ethnicity}

The prevalence of low EA has been studied mainly in females of Caucasian, European or European American descent. Whether race plays a role in the incidence and underlying aetiology of the RED-S remains speculative.

Race is a significant variable for several of the individual Triad components in non-athletic women. For example, a lower risk of $\mathrm{ED}$ is shown in African-American than Caucasian women, ${ }^{71}$ even among adolescent athletes. ${ }^{72}$ Whether the prevalence of menstrual disorders differs among racially diverse, athletic groups is currently unknown. In non-athletes, menarche occurs significantly earlier in African-American than in Caucasian or European American women. ${ }^{73}$ The BMD of African-American non-athletic females is significantly greater than that of Caucasian women, with a lower risk of osteoporosis and fracture. ${ }^{74}$ In athletes, little is known 
about the differences in BMD among ethnic groups, especially in the presence of low EA, DE/EDs and hormonal and metabolic imbalances. Stress fractures in African-American military recruits are lower than in Caucasian recruits. ${ }^{75}$ Based on preliminary data of a multicentre study, African-American and African black athletes exhibit similar symptoms of low EA, with Caucasian athletes showing greater risk of DE/EDs and menstrual dysfunction ${ }^{76}$ and no advantage for BMD in African black athletes. ${ }^{77}$ There are no published scientific studies in Hispanic and limited evidence on Asian athletes. $^{78}$

\section{Athletes with a disability}

At present there are no data available on low EA in athletes with disabilities. Individuals with spinal cord injuries, suffer from osteoporosis due to the lack of skeletal loading. ${ }^{79}$ While no data exist on EA or DE/ED patterns in athletes with a disability, their occurrence should not be overlooked. RED-S in athletes with a disability should be taken seriously due to possible comorbidities. Athletes with an amputation and who ambulate may have additional energetic challenges due to the inefficiency of movement, ${ }^{80}$ thus increasing their risk for inadvertent energy deficiency. $^{81}$

\section{Screening and diagnosis}

\section{Relative energy deficiency and EDs in sport}

The screening and diagnosis of RED-S is challenging, as symptomatology can be subtle. A high index of suspicion of the athlete at risk is needed. Early detection is crucial to improve performance and prevent long-term health consequences. Screening for RED-S should be undertaken as part of an annual Periodic Health Examination (PHE) and when an athlete presents with DE/ED, weight loss, lack of normal growth and development, menstrual dysfunction, recurrent injuries and illnesses, decreased performance or mood changes. Although various screening instruments exist, ${ }^{168283}$ they have not been validated and there is no consensus on which screening tool has the best efficacy. ${ }^{8485}$ Furthermore, these tools exclude men, disabled athletes and are not ethnically diverse.

Since low EA plays a pivotal role in the development of the RED-S, diagnosis should focus on identification of the presence and causes of the low EA. Unfortunately, there are no standardised guidelines to determine EA. EA is equivalent to EI minus the cost of exercise energy expenditure (EEE) relative to FFM or lean body mass: EA ( $\mathrm{kcal} / \mathrm{kg} \mathrm{FFM} /$ day $)=(\mathrm{EI}(\mathrm{kcal} / \mathrm{day})-\mathrm{EEE}$ $(\mathrm{kcal} /$ day $)$ ) The measurement of each of these components requires expertise and is generally imprecise. EI can be assessed by retrospective (recall) or prospective (written or electronic food diary) methods. ${ }^{86}$ EEE is usually assessed by an exercise log and tables of energy expenditure associated with sports/exercise activities, but may be supplemented where available by data collected via modern sports technology (eg, Global Positioning System Units, Heart Rate Monitors or Power Meters). Ideally, EI and EEE are measured over a similar time period that is representative of habitual practices. FFM can be quantified by methods such as dual-energy X-ray absorptiometry (DXA) and anthropometry. ${ }^{87} \mathrm{~A}$ measurement of resting metabolic rate via indirect calorimetry may provide confirmation of suppressed metabolism secondary to low EA. Underpinning factors related to an unintentional mismatch between EI and large training/competition volume, intensity or misguided weight loss practices may be relatively easy to diagnose.

The Brief Eating Disorder in Athletes Questionnaire (BEDA-Q) is a validated screening tool that shows promising results in terms of distinguishing between female elite athletes with and without ED/DE. ${ }^{88}$ The Gold Standard for the diagnosis of EDs is the Eating Disorder Examination interview (EDE-16). ${ }^{89}$ For diagnostic criteria for ED see APA. ${ }^{16}$

\section{Menstrual dysfunction}

FHA is a diagnosis of exclusion. Assessment of irregular menses should include a menstrual history assessing age of menarche, regularity of menses, use of medications, the presence of other health issues and a family menstrual history. Physical examination includes assessment of anthropometry, pubertal stage, signs of ED and secondary causes of amenorrhoea. ${ }^{83}$ Pelvic examination may reveal pregnancy or hypoestrogen-related vaginal atrophy. Laboratory assessment of haemoglobin, luteinising hormone, follicle stimulating hormone, prolactin, oestradiol, T4, thyroid stimulating hormone, pregnancy and androgen profile may be indicated. More extensive testing might include a pelvic ultrasound and endometrial sampling to rule out other gynaecological pathologies.

\section{Bone health}

In athletes with low EA, DE, ED or amenorrhoea of over 6 months, BMD should be measured by DXA. ${ }^{90}{ }^{91}$ In the adolescent, DXA should include the whole body (head excluded) in addition to the lumbar spine. ${ }^{6} 92$ As athletes in weight-bearing sports should have 5-15\% higher BMD than non-athletes ${ }^{93} 94$ a BMD Z-score <-1.0 SD warrants further attention. In the athlete population, low BMD is defined as a Z-score between -1.0 and $-2.0 \mathrm{SD}$, together with a history of nutritional deficiencies, hypoestrogenism, stress fracture or other secondary clinical risk factors for fracture. A value below -2.0 SD is considered as osteoporosis with the presence of secondary clinical risk factors. ${ }^{6}$ The recommended interval to reassess BMD via DXA scan for athletes at risk, or who are being treated for low BMD is 12 months in adults and a minimum of 6 months in adolescents. $^{95}$

\section{Treatment strategies of RED-S}

\section{Treatment strategies for low EA}

The treatment of low EA should involve an increase in EI, reduction in exercise or a combination of both. The only strategy to have received scientific scrutiny is the addition of an energy-rich supplement (eg, liquid meal product) to habitual intake and a small reduction in, or introduction of a rest day to the weekly training programme. ${ }^{96-98}$ Despite the small sample size, this intervention was successful, ${ }^{96} 97$ however, not in all studies $^{98}$ as this strategy may fail to address many underlying dietary and psychological factors. While developing a strategy to implement a diet of known and appropriate EA may be logical, it is usually impractical due to the challenges of measuring EA in the field. Therefore, a practical treatment approach to address low EA is to implement an eating plan that increases current EI by $\sim 300-600 \mathrm{kcal} /$ day $(1.2-2.4 \mathrm{MJ} /$ day) and addresses suboptimal practices related to energy spread over the day and around exercise sessions, dietary composition and food-related stress.

\section{Treatment strategies for low EA-associated menstrual dysfunction}

In collegiate athletes, weight gain is the strongest predictor of recovery of normal menstrual function. ${ }^{99-101}$ Adequate protein and carbohydrate intake is recommended to restore liver glycogen to facilitate $\mathrm{LH}$ pulsatility. ${ }^{31} 102$ The time frame for the resumption of menses varies according to the severity of the energy deficiency and the duration of the menstrual dysfunction. ${ }^{100}$

Although oral contraceptives (OCs) may be considered for athletes requiring contraception, ${ }^{103}$ these may mask the low EA, 
menstrual dysfunction and perpetuate bone loss. Injectable depot medroxyprogesterone, another form of contraception, can cause amenorrhoea and hence prolonged use can adversely affect $\mathrm{BMD},{ }^{104}$ and adolescent bone mass accrual, ${ }^{105}$ which is reversible to a certain extent on discontinuation. ${ }^{106}$ Many physicians prescribe low-dose OCs as hormone replacement in the amenorrheic athlete, however, this intervention does not correct the aetiological cause of relative energy deficiency and may compromise the attainment of peak bone density. ${ }^{107}$

Treatment options to restore fertility may include increasing EA. Pharmacological agents may be necessary to stimulate ovulation in luteal phase deficiency. ${ }^{27}$ Attention must be paid to infertility treatments identified in the WADA Prohibited List. ${ }^{58}$

\section{Treatment strategies to optimise bone health}

Strategies to reverse bone loss in women with FHA parallel those used for amenorrheic women with anorexia. ${ }^{108}$ In the latter population, weight gain with or without the subsequent resumption of menses restores the coupling of bone formation and resporption ${ }^{109} 110$ and improves BMD. ${ }^{109}$ However, full recovery may not be feasible, as bone microarchitecture is also impaired. ${ }^{111}$ EI alone increases bone mass by $1-10 \%$ in women with anorexia. ${ }^{110} 112$ It is essential to restore the energy and oestrogen-dependent mechanisms of bone loss in order to improve mineralisation of trabecular bone and growth of cortical bone. ${ }^{41}$ Mechanical loading and high-impact sports are known to positively affect $\mathrm{BMD}^{113}{ }^{114}$ as well as bone geometry. ${ }^{115} 116$ Programmes of high-impact loading and resistance training should be implemented at least 2-3 days/week for athletes in non-weight bearing sports and/or those with decreased BMD. ${ }^{6}$

The athlete diet should include $1500 \mathrm{mg} /$ day of calcium through dietary sources with supplementation if required. ${ }^{117}$ The Endocrine Society Guideline (2011) recommends maintaining vitamin $\mathrm{D}[25(\mathrm{OH}) \mathrm{D}]$ blood levels above $32-50 \mathrm{ng} / \mathrm{mL}$, with 1500-2000 IU/day of vitamin D. ${ }^{118}{ }^{119}$ Vitamin D deficiency is common in northern latitudes, especially during winter when there are fewer hours of sunlight and among athletes who train indoors. ${ }^{120} 121$ Other factors include dark pigmented skin, and the use of sunscreen. A recent meta-analysis of vitamin D supplementation found a positive effect in femoral and hip BMD, with no effect in the spine. ${ }^{122}$

Transdermal oestradiol (given with cyclic progesterone) has shown some success in increasing BMD in patients with anorexia. ${ }^{123}$ In some studies, combination OCs containing 20-35 $\mu \mathrm{g}$ of oestradiol have maintained or improved BMD in amenorrheic athletes. ${ }^{124} 125$ However, use of the OCP in athletes with FHA have been reported to have a detrimental effect on BMD through the suppression of androgen secretion and cause premature closure of the epiphyses compromising growth of the long bones in adolescents. ${ }^{126}$

Bisphosphonates, which inhibit the resorption of bone, are not recommended for women of reproductive age, as they are stored in bone for prolonged amounts of time and have been shown to be teratogenic. ${ }^{127} 128$ Other therapies including raloxifene (a selective oestrogen receptor modulator or SERM), parathyroid hormone peptides, teriperatide and calcitonin, are also not approved for use in premenopausal women. Some novel potential therapies are being developed, but clinical trials are lacking. ${ }^{129} 130$ These include insulin-derived growth factor (a bone anabolic agent) ${ }^{131} 132$ and leptin which can be used to stimulate appetite, thus effecting resumption of menses and subsequent improvement in BMD. ${ }^{133-135}$

In men, detection and correction of any underlying pathology is essential, including testosterone therapy with hypogonadism and osteoporosis. Bisphosphonates may be used as monotherapy, as consolidative therapy after a course of teriperatide administration or in combination with hormonal replacement. ${ }^{136}$ Denusomab and strontium ranelate also increase BMD in men with osteoporosis. ${ }^{137}$

\section{Treatment strategies for psychological sequelae}

If an athlete will not or cannot follow the treatment plan, a psychological factor is generally present. Athlete resistance to treatment usually increases with the severity of the eating problem. ${ }^{138}$ Treatment should be provided by a mental health professional knowledgeable about the management of EDs in athletes. The frequency, types, intensity and duration of psychological treatment depend on the severity, chronicity and the medical and psychological complications of the eating problem,

Table 1 Relative Energy Deficiency in Sport risk assessment model for sport participation (modified from Skårderud et al) ${ }^{140}$

\begin{tabular}{|c|c|c|}
\hline High risk: no start red light & Moderate risk: caution yellow light & Low risk: green light \\
\hline \multirow[t]{5}{*}{$\begin{array}{l}\text { Anorexia nervosa and other serious eating disorders } \\
\text { Other serious medical (psychological and physiological) } \\
\text { conditions related to low energy availability } \\
\text { Extreme weight loss techniques leading to dehydration } \\
\text { induced haemodynamic instability and other } \\
\text { life-threatening conditions }\end{array}$} & $\begin{array}{l}\text { Prolonged abnormally low } \% \text { body fat measured by DXA or } \\
\text { anthropometry using The International Society for the Advancement of } \\
\text { Kinanthropometry ISAK }{ }^{141} \text { or non-ISAK approaches }{ }^{142} \\
\text { Substantial weight loss ( } 5-10 \% \text { body mass in } 1 \text { month) } \\
\text { - Attenuation of expected growth and development in adolescent athlete }\end{array}$ & $\begin{array}{l}\text { Healthy eating habits with } \\
\text { appropriate energy } \\
\text { availability }\end{array}$ \\
\hline & $\begin{array}{l}\text { Abnormal menstrual cycle: FHA amenorrhoea }>6 \text { months } \\
\text { Menarche }>16 \text { years } \\
\text { Abnormal hormonal profile in men }\end{array}$ & $\begin{array}{l}\text { Normal hormonal and } \\
\text { metabolic function }\end{array}$ \\
\hline & $\begin{array}{l}\text { Reduced BMD (either from last measurement or Z-score }<-1 \text { SD). } \\
\text { History of } 1 \text { or more stress fractures associated with hormonal/menstrual } \\
\text { dysfunction and/or low EA }\end{array}$ & $\begin{array}{l}\text { Healthy BMD as expected for } \\
\text { sport, age and ethnicity } \\
\text { Healthy musculoskeletal } \\
\text { system }\end{array}$ \\
\hline & $\begin{array}{l}\text { Athletes with physical/psychological complications related to low EA/ } \\
\text { disordered eating - ECG abnormalities- Laboratory abnormalities }\end{array}$ & \\
\hline & $\begin{array}{l}\text { Prolonged relative energy deficiency } \\
\text { Disordered eating behaviour negatively affecting other team members } \\
\text { Lack of progress in treatment and/or non-compliance }\end{array}$ & \\
\hline
\end{tabular}


Table 2 The Relative Energy Deficiency in Sport Decision-based Return-to-Play Model (modified from Creighton et al ${ }^{143}$ )

\begin{tabular}{llll}
\hline Steps & Risk modifiers & Criteria & Red-S-specific criteria \\
\hline $\begin{array}{l}\text { Step 1 } \\
\text { Evaluation of health status }\end{array}$ & Medical factors & $\begin{array}{l}\text { Patient demographics } \\
\text { Symptoms }\end{array}$ & $\begin{array}{l}\text { Age, sex (see Yellow light column of table 1) } \\
\text { Recurrent dieting, menstrual health, bone health } \\
\text { Weight loss/fluctuations, weakness } \\
\text { Hormones, electrolytes, ECG and DXA } \\
\text { Depression, anxiety, disordered eating/eating disorder } \\
\end{array}$ \\
& & Medical history & Abnormal hormonal and metabolic function \\
& & Signs & Stress fracture \\
Laboratory tests & Weight sensitive, leanness sport \\
Step 2 & Psychological health & Individual vs team sport \\
Evaluation of participation risk & Potential seriousness & Elite vs Re-creational \\
Step 3 & Sport risk modifiers & Type of sport & In/out of season, travel, environmental factors \\
Decision modification & & Position played & Desire to compete \\
& Competitive level & Coach, team owner, athlete family and sponsors \\
& If restricted from competition
\end{tabular}

as well as the comorbid psychological disorders that often accompany such problems. Ideally, eating problems can be treated on an outpatient basis. Medical complications, risk of self-harm and lack of progress in outpatient treatment indicate a need for more intensive treatment regimens including inpatient, residential, partial hospitalisation and intensive outpatient programmes. Treatment is usually required for several months. Treatment modalities might include cognitive behavioural therapy, dialectical behaviour therapy or family-based therapy. Comorbid conditions, such as depression, anxiety and other psychological problems also need to be addressed. Pharmacotherapy may also be recommended; antidepressants are the class of medications most often prescribed. ${ }^{139}$

\section{Clinical models for sport participation and return-to-play \\ Risk assessment for sport participation}

There are limited evidence-based guidelines to assist the athlete healthcare team in the assessment for sport participation clearance with RED-S. Based on the guidelines from the Norwegian Olympic Training Center ${ }^{140}$ and the collective expertise of the IOC Consensus group, a new model of criteria to assess risk for sport participation has been developed (table 1). This model can be incorporated into the PHE. The criteria for this model are based on those used at the Norwegian Olympic Training Center, ${ }^{140}$ and also recommended by the IOC Body Composition, Health and Performance Working group. ${ }^{8}$

It is recommended that athletes in the 'High Risk-Red Light' risk category should not be cleared to participate in sport. Owing to the severity of their clinical presentation, sport participation may pose serious jeopardy to their health and may also distract the athlete from devoting the attention needed for treatment and recovery. ${ }^{138}$ These athletes should receive treatment using a written treatment contract (see online supplementary appendix 1). Athletes in the 'Moderate RiskYellow Light' risk category should be cleared for sport participation only with supervised participation and a medical treatment plan. Re-evaluation of the athlete's risk assessment should occur at regular intervals of 1-3 months depending on the clinical scenario to assess compliance and to detect changes in clinical status.

\section{Return-to-play}

Decision-making regarding return-to-play (RTP) following time away from sport for recovery from injury and/or illness is based on the assessment of the athlete's health and the requirements of his/her sport. ${ }^{143} 144$ Table 3 adapts Creightons's RTP Model and the guidelines from the Norwegian group ${ }^{140}$ to the athlete with RED-S through the addition of RED-S specific criteria.

The RED-S Risk Assessment Model is adapted to aid clinicians' decision-making for determining an athlete's readiness to return to sport. Following clinical reassessment utilising the three-step evaluation outlined in table 2 , athletes can be reclassified into the 'High Risk-Red Light', 'Moderate Risk-Yellow Light' or 'Low Risk-Green Light' categories. The RED-S return-to-play model (table 3) outlines the sport activity recommended for each risk category.

\section{Recommendations to address RED-S}

The following recommendations are formulated based on a review of the scientific evidence and the collective expertise of the IOC Consensus group relating to the RED-S.

\section{Athlete entourage recommendations}

The athlete's entourage can prevent RED-S through implementation of the following strategies:

Table 3 The Relative Energy Deficiency in Sport Return-to-Play Model (modified from Skårderud et al, 2012) ${ }^{140}$

\begin{tabular}{ll}
\hline High risk red light & Moderate risk yellow light \\
No competition & Mapervised training allowed when medically cleared for adapted training once medically cleared under supervision \\
S Use of written contract (see supplementary appendix 1)
\end{tabular}


- Educational programmes on RED-S, healthy eating, nutrition, EA, the risks of dieting and how these affect health and performance.

- Reduction of emphasis on weight, emphasising nutrition and health as a means to enhance performance.

- Development of realistic and health-promoting goals related to weight and body composition.

- Avoidance of critical comments about an athlete's body shape/weight.

- Use of reputable sources of information.

- Promotion of awareness that good performance does not always mean the athlete is healthy.

- Encouragement and support of appropriate, timely and effective treatment.

Healthcare professional recommendations

HealthCare professionals can decrease the health implications of RED-S through the following interventions:

- Identification of a multidisciplinary athlete health support team including sports physician, nutritionist, psychologist, physiotherapist and physiologist.

- Education of the medical team in the detection and treatment of the RED-S.

- Implementation of the RED-S Risk Assessment Model in the PHE and the RED-S RTP Model.

Sport organisation recommendations

Sport organisations such as International Federations, National Olympic Committees and National Sport Federations can prevent RED-S through the implementation of:

- Preventative educational programmes;

- Rule modifications/changes to address weight-sensitive issues in sport;

- Policies for coaches on the healthy practice of managing athlete eating behaviour, weight and body composition.

Research recommendations

Research institutions should focus on research and evaluation of:

- The aetiology and treatment of athletes with RED-S including males, ethnic and disabled populations;

- Design and validation of tools to accurately measure EA in the clinical setting;

- The validation of screening tools and treatment programmes such as the RED-S Risk Assessment Model and RED-S RTP Model.

\section{What is already known on this topic?}

- The International Olympic Committee (IOC) has published a Consensus Statement and Position Stand (2005) on the Female Athlete Triad outlining the pathophysiology and prevalence of this syndrome.

- Low energy availability is the aetiological process underpinning the development of the Female Athlete Triad.

- Prevalence measures of the Triad indicate that female athletes are particularly vulnerable to this syndrome in sports where leanness and/or weight are important due to their role in performance, appearance or requirement to meet a competition weight category.
How might this IOC consensus statement impact on clinical practice in the near future?

- Scientific evidence and clinical experience around the effects of low energy availability shows that several body systems in addition to the reproductive and musculoskeletal systems are affected, and that men are at risk as well as women.

- Based on the evidence, a broader term, which includes what has so far been called the 'Female Athlete Triad', is introduced: Relative Energy Deficiency in Sport (RED-S).

- Owing to the potential serious health consequences of this syndrome, there is a need in the clinical realm to establish a 'Sport Risk Assessment' model to protect the health and well-being of athletes with this syndrome.

- 'Return-to-Play' guidelines will assist the athlete health support team in the safe return of the affected athlete to sport participation.

- Recommendations for sport organisations, athlete entourage and research institutions will result in future awareness, understanding and further evidence-based knowledge of the RED-S.

\section{Author affiliations}

${ }^{1}$ Department of Family Medicine, Michael G. DeGroote School of Medicine,

McMaster University, Hamilton, Ontario, Canada

${ }^{2}$ Department of Sports Medicine, The Norwegian School of Sport Sciences, Oslo,

Norway

${ }^{3}$ Department of Sports Nutrition, Australian Institute of Sport, Belconnen, Australia

${ }^{4}$ University of Northern Colorado, University of Colorado Medical School, Lakewood,

Colorado, USA

${ }^{5}$ Orthopedic Department, Hadassah-Hebrew University Medical Center, Jerusalem, Israel

${ }^{6}$ Department of Family Medicine, Faculty of Medicine \& Dentistry, Glen Sather Sports Medicine Clinic, University of Alberta, Edmonton, Alberta, Canada

${ }^{7}$ Health Sciences Department and United States Olympic Committee, University of

Colorado, Colorado Springs, Colorado, USA

${ }^{8}$ The Victory Program at McCallum Place, St. Louis, Missouri, USA

${ }^{9}$ IOC Medical and Scientific Department, Lausanne, Switzerland

Acknowledgements The authors would like to acknowledge the work of Barbara Drinkwater in the field of the Female Athlete Triad, and for her ongoing support of the advancement of science in this domain.

Contributors MM and JS-B were involved in the substantial contributions to conception and design, co-coordinator of IOC Expert Group + Consensus meeting, drafting and revising the manuscript and final version to be published. $L B, S C N C$, $\mathrm{CL}$, NM and RS, were the members of IOC Expert Group, contribution at Consensus meeting, substantial contribution to drafting and final revision of the manuscript to be published. KS was the contributor at Consensus meeting, final revision of the manuscript to be published. RB was the Director IOC Medical \& Scientific

Department, participant at Consensus meeting, final revision of the manuscript to be published. AL was the Chairman of IOC Medical Commission, participant at Consensus meeting, final revision of the manuscript to be published.

Funding The Consensus meeting was funded by the International Olympic Committee.

Competing interests None.

Provenance and peer review Commissioned; internally peer reviewed.

\section{REFERENCES}

1 Olympic Charter. International Olympic Committee. Lausanne, Switzerland, 2011. http://www.olympic.org/Documents/olympic_charter_en.pdf (retrieved 23 Nov 2013).

2 Olympic Movement Medical Code. In force as from 1 Oct 2009. http://www.olympic. org/PageFiles/61597/Olympic_Movement_Medical_Code_eng.pd (retrieved 23 Nov 2013).

3 Committee Medical Commission Working Group Women in Sport:position stand on the female athlete triad.International Olympic Committee 2005. http://www. olympic.org/Documents/Reports/EN/en_report_917.pdf (Retrieved 23 Nov 2013). 
4 IOC Consenus Statement on the Female Athlete Triad. $2005 \mathrm{http}: / \mathrm{www}$.olympic. org/Documents/Reports/EN/en_report_917.pd (Retrieved 23 Nov 2013).

5 Drinkwater BL, Nilson $\mathrm{K}$, Ott $\mathrm{S}$, et al. Bone mineral density after resumption of menses in amenorrheic athletes. JAMA 1986;256:380-2.

6 Nattiv A, Loucks AB, Manore MM, et al. American College of Sports Medicine position stand. The female athlete triad. Med Sci Sports Exerc 2007;39:1867-82

7 Loucks AB. Energy balance and body composition in sports and exercise. I Sports Sci 2004;22:1-14.

8 Sundgot-Borgen J, Meyer NL, Lohman TG, et al. How to minimise the health risks to athletes who compete in weight-sensitive sports review and position statement on behalf of the Ad Hoc Research Working Group on Body Composition, Health and Performance, under the auspices of the IOC Medical Commission. Br I Sports Med 2013;47:1012-22.

9 IOC Nutrition Working Group. Nutrition for Athletes: A Practical Guide to Eating for Health and Performance 2012.

10 Loucks $A B$, Heath EM. Induction of low-T3 syndrome in exercising women occurs at a threshold of energy availability. Am J Physiol 1994;266(3 Pt 2):R817-23.

11 Ihle $R$, Loucks $A B$. Dose-response relationships between energy availability and bone turnover in young exercising women. J Bone Miner Res 2004;19:1231-40.

12 Loucks $A B$, Kiens B, Wright HH. Energy availability in athletes. I Sports Sci 2011:29(Suppl 1):S7-15.

13 Koehler K, Achtzehn S, Braun H, et al. Comparison of self-reported energy availability and metabolic hormones to assess adequacy of dietary energy intake in young elite athletes. Appl Physiol Nutr Metab 2013;38:725-33.

14 Reed JL, De Souza MJ, Williams NI. Changes in energy availability across the season in Division I female soccer players. I Sports Sci 2013;31:314-24.

15 Sundgot-Borgen J, Torstveit MK. Aspects of disordered eating continuum in elite high-intensity sports. Scand I Med Sci Sports 2010;20(Suppl 2):112-21.

16 American Psychiatric Association. Diagnostic and statistical manual of mental disorders, 5th edn. Washington, DC: American Psychiatric Association, 2013.

17 Stice E, South $\mathrm{K}$, Shaw $\mathrm{H}$. Future directions in etiologic, prevention, and treatment research for eating disorders. J Clin Child Adolesc Psychol 2012:41:845-55.

18 Martinsen $M$, Sundgot-Borgen J. Higher prevalence of eating disorders among adolescent elite athletes than controls. Med Sci Sports Exerc 2013:45:1188-97.

19 ACOG Committee on Adolescent Health Care ACOG Committee Opinion No. 349, November 2006: menstruation in girls and adolescents: using the menstrual cycle as a vital sign. Obstet Gynecol 2006;108:1323-8.

20 American Society of Reproductive Medicine Practice Committee. Current evaluation of amenorrhea — has an update (reviewed June 2008). Fert Steril 2008:90:S219-25.

21 Redman LM, Loucks AB. Menstrual disorders in athletes. Sports Med 2005:35:747-55.

22 Abraham SF, Beumont PJ, Fraser IS, et al. Body weight, exercise and menstrual status among ballet dancers in training. Br J Obstet Gynaecol 1982;89:507-10.

23 Dusek T. Influence of high intensity training on menstrual cycle disorders in athletes. Croat Med J 2001:42:79-82.

24 Beals KA, Manore MM. Disorders of the female athlete triad among collegiate athletes. Int I Sport Nutr Exerc Metab 2002;12:281-93.

25 De Souza MJ, Toombs RJ, Scheid JL, et al. High prevalence of subtle and severe menstrual disturbances in exercising women: confirmation using daily hormone measures. Hum Reprod 2010;25:491-503.

26 Ellison PT, Lager C. Moderate recreational running is associated with lowered salivary progesterone profiles in women. Am J Obstet Gynecol 1986;154: $1000-3$.

27 Sonntag B, Ludwig M. An integrated view on the luteal phase: diagnosis and treatment in subfertility. Clin Endocrinol (Oxf) 2012;77:500-7.

28 Wade GN, Jones JE. Neuroendocrinology of nutritional infertility. Am J Physiol Regul Integr Comp Physiol 2004;287:R1277-96.

29 Areta JL, Burke LM, Ross ML, et al. Timing and distribution of protein ingestion during prolonged recovery from resistance exercise alters myofibrillar protein synthesis. J Physiol 2013;591(Pt 9):2319-31.

30 Rickenlund A, Eriksson MJ, Schenck-Gustafsson K, et al. Amenorrhea in female athletes is associated with endothelial dysfunction and unfavorable lipid profile. J Clin Endocrinol Metab 2005;90:1354-9.

31 Loucks AB, Thuma JR. Luteinizing hormone pulsatility is disrupted at a threshold of energy availability in regularly menstruating women. J Clin Endocrinol Metab 2003;88:297-311.

32 Nappi RE, Facchinetti F. Psychoneuroendocrine correlates of secondary amenorrhea. Arch Womens Ment Health 2003;6:83-9.

33 Baxter-Jones $A D$, Faulkner RA, Forwood MR, et al. Bone mineral accrual from 8 to 30 years of age: an estimation of peak bone mass. I Bone Miner Res 2011:26:1729-39.

34 Seifert-Klauss V, Schmidmayr M, Hobmaier E, et al. Progesterone and bone: a closer link than previously realized. Climacteric 2012;15(Suppl 1):26-31.

35 Li D, Hitchcock CL, Barr Sl, et al. Negative spinal bone mineral density changes and subclinical ovulatory disturbances - prospective data in healthy premenopausal women with regular menstrual cycles. Epidemiol Rev 2014:36:137-47.

36 Abu EO, Horner A, Kusec $V$, et al. The localization of androgen receptors in human bone. J Clin Endocrinol Metab 1997:82:3493-7.
37 Hind K, Truscott JG, Evans JA. Low lumbar spine bone mineral density in both male and female endurance runners. Bone 2006;39:880-5.

38 Vanderschueren $\mathrm{D}$, Vandenput L, Boonen S, et al. Androgens and bone. Endocr Rev 2004;25:389-425.

39 Vandenput L, Ohlsson C. Sex steroid metabolism in the regulation of bone health in men. J Steroid Biochem Mol Biol 2010;121:582-8.

40 Fuqua JS, Rogol AD. Neuroendocrine alterations in the exercising human: implications for energy homeostasis. Metabolism 2013;62:911-21.

41 Ackerman KE, Putman M, Guereca G, et al. Cortical microstructure and estimated bone strength in young amenorrheic athletes, eumenorrheic athletes and non-athletes. Bone 2012;51:680-7.

42 Lambrinoudaki I, Papadimitriou D. Pathophysiology of bone loss in the female athlete. Ann N Y Acad Sci 2010;1205:45-50.

43 Keen $A D$, Drinkwater $B L$. Irreversible bone loss in former amenorrheic athletes. Osteoporos Int 1997;7:311-15.

44 Chen YT, Tenforde AS, Fredericson M. Update on stress fractures in female athletes: epidemiology, treatment, and prevention. Curr Rev Musculoskelet Med 2013:6:173-81

45 McCabe MP, Smyth MP, Richardson DR. Current concept review: vitamin D and stress fractures. Foot Ankle Int 2012;33:526-33.

46 Wentz L, Liu PY, llich JZ, et al. Dietary and training predictors of stress fractures in female runners. Int I Sport Nutr Exerc Metab 2012;22:374-82.

47 Nattiv A. Stress fractures and bone health in track and field athletes. J Sci Med Sport 2000;3:268-79.

48 Schnackenburg KE, Macdonald HM, Ferber R, et al. Bone quality and muscle strength in female athletes with lower limb stress fractures. Med Sci Sports Exerc 2011:43:2110-19.

49 Marx RG, Saint-Phard D, Callahan LR, et al. Stress fracture sites related to underlying bone health in athletic females. Clin I Sport Med 2001;11:73-6.

50 Tenforde AS, Sayres LC, McCurdy ML, et al. Identifying sex-specific risk factors for stress fractures in adolescent runners. Med Sci Sports Exerc 2013;45:1843-51.

51 Duckham RL, Peirce N, Meyer $C$, et al. Risk factors for stress fracture in female endurance athletes: a cross-sectional study. BMJ Open 2012;19;2:pii e001920.

52 Okamoto S, Arai Y, Hara K, et al. A displaced stress fracture of the femoral neck in an adolescent female distance runner with female athlete triad: a case report. Sports Med Arthrosc Rehabil Ther Technol 2010;2:6.

53 Goolsby MA, Barrack MT, Nattiv A. A displaced femoral neck stress fracture in an amenorrheic adolescent female runner. Sports Health 2012;4:352-6.

54 Constantini NW. Medical concerns of the dancer. Book of Abstracts, XXVII FIMS World Congress of Sports Medicine, Budapest, Hungary, 2002:151.

55 Hagmar M, Hirschberg AL, Berglund L, et al. Special attention to the weight-control strategies employed by Olympic athletes striving for leanness is required. Clin J Sport Med 2008;18:5-9.

56 Thein-Nissenbaum JM, Rauh MJ, Carr KE, et al. Associations between disordered eating, menstrual dysfunction, and musculoskeletal injury among high school athletes. J Orthop Sports Phys Ther 2011;41:60-9.

57 Vanheest JL, Rodgers $C D$, Mahoney $C E$, et al. Ovarian Suppression Impairs Sport Performance in Junior Elite Female Swimmers. Med Sci Sports Exerc 2014:46:156-66.

58 http://www.wada-ama.org/en/world-anti-doping-program/ sports-and-anti-doping-organizations/international-standards/prohibited-list/

59 Vogt S, Heinrich L, Schumacher YO, et al. Energy intake and energy expenditure of elite cyclists during preseason training. Int I Sports Med 2005;26:701-6.

60 Müller W, Groschl W, Müller $R$, et al. Underweight in ski jumping: the solution of the problem. Int I Sports Med 2006;27:926-34.

61 Baum A. Eating disorders in the male athlete. Sports Med 2006:36:1-6.

62 Ferrand C, Brunet E. Perfectionism and risk for disordered eating among young French male cyclists of high performance. Percept Mot Skills 2004;99(3 Pt 1):959-67.

63 Dolan E, McGoldrick A, Davenport C, et al. An altered hormonal profile and elevated rate of bone loss are associated with low bone mass in professional horse-racing jockeys. J Bone Miner Metab 2012;30:534-42.

64 Stewart AD, Hannan J. Total and regional bone density in male runners, cyclists, and controls. Med Sci Sports Exerc 2000;32:1373-7.

65 Hetland ML, Haarbo J, Christiansen C. Low bone mass and high bone turnover in male long distance runners. J Clin Endocrinol Metab 1993;77:770-5.

66 Smathers AM, Bemben MG, Bemben DA. Bone density comparisons in male competitive road cyclists and untrained controls. Med Sci Sports Exerc 2009:41:290-6.

67 Rector RS, Rogers R, Ruebel M, et al. Participation in road cycling vs running is associated with lower bone mineral density in men. Metabolism 2008:57:226-32.

68 Guillaume G, Chappard D, Audran M. Evaluation of the bone status in high-level cyclists. J Clin Densitom 2012;15:103-7.

69 Nichols JF, Palmer JE, Levy SS. Low bone mineral density in highly trained male master cyclists. Osteoporos Int 2003:14:644-9.

70 Hackney AC. Effects of endurance exercise on the reproductive system of men: the 'exercise-hypogonadal male condition'. J Endocrinol Invest 2008;31:932-8. 
71 Pernick Y, Nichols JF, Rauh MJ, et al. Disordered eating among a multi-racial/ ethnic sample of female high-school athletes. J Adolesc Health 2006;38:689-95.

72 Rhea DJ. Eating disorder behaviors of ethnically diverse urban female adolescent athletes and non-athletes. J Adolesc 1999;22:379-88.

73 Adams Hillard PJ. Menstruation in adolescents: what's normal? Medscape J Med 2008;10:295.

74 Fang J, Freeman R, Jeganathan $\mathrm{R}$, et al. Variations in hip fracture hospitalization rates among different race/ethnicity groups in New York City. Ethn Dis 2004:14:280-4.

75 Lappe JM, Stegman MR, Recker RR. The impact of lifestyle factors on stress fractures in female Army recruits. Osteoporos Int 2001;12:35-42.

76 Kark S, Ochoa EA, Harris MM, et al. The Female Athlete Triad: Preliminary data from a multi-site study on triad and race. Med Sci Sports Exerc 2012; (in press).

77 Wright $\mathrm{HH}$, Bota CR, Havemann-Nel L. White and black student athletes have a more favourable body composition and bone mineral density than non-athletes. Med Sci Sports Exerc 2012;44:269.

78 Quah YV, Poh BK, Ng LO, et al. The female athlete triad among elite Malaysian athletes: prevalence and associated factors. Asia Pac J Clin Nutr 2009;18: 200-8.

79 Jiang SD, Jiang LS, Dai LY. Mechanisms of osteoporosis in spinal cord injury. Clin Endocrinol (Oxf) 2006:65:555-65.

80 Bragaru M, Dekker R, Geertzen JH, et al. Amputees and sports: a systematic review. Sports Med 2011;41:721-40.

81 Goosey-Tolfrey VL, Crosland J. Nutritional practices of competitive British wheelchair games players. Adapt Phys Activ Q 2010;27:47-59.

82 Ljungqvist $A$, Jenoure $P$, Engebretsen $L$, et al. The International Olympic Committee (IOC) Consensus Statement on periodic health evaluation of elite athletes March 2009. Br J Sports Med 2009;43:631-43.

83 Javed A, Tebben PJ, Fischer PR, et al. Female athlete triad and its components: toward improved screening and management. Mayo Clin Proc 2013;88: 996-1009.

84 Rumball JS, Lebrun CM. Use of the preparticipation physical examination form to screen for the female athlete triad in Canadian interuniversity sport universities. Clin J Sport Med 2005:15:320-5.

85 Mencias T, Noon M, Hoch AZ. Female athlete triad screening in National Collegiate Athletic Association Division I athletes: is the preparticipation evaluation form effective? Clin J Sport Med 2012;22:122-5.

86 Burke LM, Cox GR, Culmmings NK, et al. Guidelines for daily carbohydrate intake: do athletes achieve them? Sports Med 2001;31:267-99.

87 Ackland TR, Lohman TG, Sundgot-Borgen J, et al. Current status of body composition assessment in sport: review and position statement on behalf of the ad hoc research working group on body composition health and performance, under the auspices of the I.O.C. Medical Commission. Sports Med 2012;42:227-49.

88 Martinsen M, Sundgot-Borgen J. The development of the Brief Eating Disorder in Athletes Questionnaire (BEDA-Q). Med Sci Sports Exerc 2014 (In Press).

89 Fairburn CG, Cooper Z, O'Connor ME. Eating Disorder Examination (Edition 16.0D). In: Fairburn CG ed. Cognitive behavior therapy and eating disorders. New York: The Guilford Press, 2008:265-308.

90 De Souza MJ, Nattiv A, Joy E, et al. 2014 Female Athlete Triad Coalition Consensus Statement on Treatment and Return to Play of the Female Athlete Triad: 1st International Conference held in San Francisco, California, May 2012 and 2nd International Conference held in Indianapolis, Indiana, May 2013. $\mathrm{Br}$ Sports Med 2014;48:289

91 Bachrach LK, Sills IN. Clinical report-bone densitometry in children and adolescents. Pediatrics 2011;127:189-94.

92 Khan AA, Bachrach L, Brown JP, et al. Standards and guidelines for performing central dual-energy $\mathrm{x}$-ray absorptiometry in premenopausal women, men, and children. J Clin Densitom 2004;7:51-64.

93 Duckham RL, Baxter-Jones AD, Johnston JD, et al. Does physical activity in adolescence have site and sex specific benefits on young adult bone size, content and estimated strength? J Bone Miner Res 2014:29:479-86.

94 Tenforde AS, Fredericson M. Influence of sports participation on bone health in the young athlete: a review of the literature. PM R 2011;3:861-7.

95 http://www.iscd.org/official-positions/2013-ascd-official-positions-adult/

96 Dueck CA, Matt KS, Manore MM, et al. Treatment of athletic amenorrhea with a diet and training intervention program. Int J Sport Nutr 1996;6:24-40.

97 Kopp-Woodroffe SA, Manore MM, Dueck CA, et al. Energy and nutrient status of amenorrheic athletes participating in a diet and exercise training intervention program. Int J Sport Nutr 1999;9:70-88.

98 Guebels CP, Kam LC, Maddalozzo GF, et al. Active Women Before/After an Intervention Designed to Restore Menstrual Function: Resting Metabolic Rate and Comparison of Four Methods to Quantify Energy Expenditure and Energy Availability. Int J Sport Nutr Exerc Metab 2013; (in press)

99 Fredericson M, Kent K. Normalization of bone density in a previously amenorrheic runner with osteoporosis. Med Sci Sports Exerc 2005;37:1481-6.

100 Arends JC, Cheung MY, Barrack MT, et al. Restoration of menses with nonpharmacologic therapy in college athletes with menstrual disturbances: a 5-year retrospective study. Int J Sport Nutr Exerc Metab 2012;22:98-108.
101 Mallinson RJ, Williams NI, Olmsted MP, et al. A case report of recovery of menstrual function following a nutritional intervention in two exercising women with amenorrhea of varying duration. J Int Soc Sports Nutr 2013;10:34.

102 Loucks AB, Verdun M, Heath EM. Low energy availability, not stress of exercise, alters LH pulsatility in exercising women. J Appl Physiol (1985) 1998:84:37-46.

103 Blyth MJ, Diaz A. American Academy of Pediatrics Committee on Adolescence. Contraception and adolescents. Pediatrics 2007;120:1135-48.

104 Hergenroeder AC, Smith EO, Shypailo R, et al. Bone mineral changes in young women with hypothalamic amenorrhea treated with oral contraceptives, medroxyprogesterone, or placebo over 12 months. Am J Obstet Gynecol 1997; 176:1017-25.

105 Zhang $\mathrm{MH}$, Zhang $\mathrm{W}$, Zhang $\mathrm{AD}$, et al. Effect of depot medroxyprogesterone acetate on bone mineral density in adolescent women. Chin Med J (Engl) 2013:126:4043-7.

106 Kaunitz AM, Arias R, McClung M. Bone density recovery after depot medrozyprogesterone acetate injectable contraception use. Contraception 2008;77:67-76

107 Hartard M, Kleinmond C, Wiseman M, et al. Detrimental effect of oral contraceptives on parameters of bone mass and geometry in a cohort of 248 young women. Bone 2007;40:444-50

108 Vescovi JD, Jamal SA, De Souza MJ. Strategies to reverse bone loss in women with functional hypothalamic amenorrhea: a systematic review of the literature. Osteoporos Int 2008:19:465-78.

109 Misra M, Prabhakaran R, Miller KK, et al. Weight gain and restoration of menses as predictors of bone mineral density change in adolescent girls with anorexia nervosa-1. J Clin Endocrinol Metab 2008;93:1231-7.

110 Compston JE, McConachie C, Stott C, et al. Changes in bone mineral density, body composition and biochemical markers of bone turnover during weight gain in adolescents with severe anorexia nervosa: a 1-year prospective study. Osteoporos Int 2006:17:77-84.

111 Ackerman KE, Misra M. Bone health and the female athlete triad in adolescent athletes. Phys Sports Med 2011:39:131-41.

112 Viapiana O, Gatti D, Dalle GR, et al. Marked increases in bone mineral density and biochemical markers of bone turnover in patients with anorexia nervosa gaining weight. Bone 2007;40:1073-7.

113 Nichols JF, Rauh MJ, Barrack MT, et al. Bone mineral density in female high school athletes: interactions of menstrual function and type of mechanical loading. Bone 2007:41:371-7.

114 Vicente-Rodriguez $\mathrm{G}$. How does exercise affect bone development during growth? Sports Med 2006:36:561-9.

115 Michalopoulou M, Kambas A, Leontsini D, et al. Physical activity is associated with bone geometry of premenarcheal girls in a dose-dependent manner. Metabolism 2013:62:1811-18.

116 Maimoun L, Coste 0 , Philibert $P$, et al. Peripubertal female athletes in high-impact sports show improved bone mass acquisition and bone geometry. Metabolism 2013;62:1088-98.

117 Kitchin B. Nutrition counseling for patients with osteoporosis: a personal approach. J Clin Densitom 2013;16:426-31.

118 Holick MF, Binkley NC, Bischoff-Ferrari HA, et al. Evaluation, treatment, and prevention of vitamin $D$ deficiency: an Endocrine Society clinical practice guideline. J Clin Endocrinol Metab 2011;96:1911-30.

119 Heber D, Greenway FL, Kaplan LM, et al. Endocrine and nutritional management of the post-bariatric surgery patient: an Endocrine Society Clinical Practice Guideline. J Clin Endocrinol Metab 2010:95:4823-43.

120 Lovell G. Vitamin D status of females in an elite gymnastics program. Clin J Sport Med 2008:18:159-61.

121 Constantini NW, Arieli R, Chodick G, et al. High prevalence of vitamin D insufficiency in athletes and dancers. Clin J Sport Med 2010;20:368-71.

122 Reid IR, Bolland MJ, Grey A. Effects of vitamin D supplements on bone mineral density: a systematic review and meta-analysis. Lancet 2013;383:146-55.

123 Misra M, Klibanski A. Bone health in anorexia nervosa. Curr Opin Endocrinol Diabetes Obes 2011;18:376-82.

124 Cobb KL, Bachrach LK, Sowers M, et al. The effect of oral contraceptives on bone mass and stress fractures in female runners. Med Sci Sports Exerc 2007:39:1464-73.

125 Warren MP, Miller KK, Olson WH, et al. Effects of an oral contraceptive (norgestimate/ethinyl estradiol) on bone mineral density in women with hypothalamic amenorrhea and osteopenia: an open-label extension of a double-blind, placebo-controlled study. Contraception 2005:72:206-11.

126 Scheid JL, Toombs RJ, Ducher G, et al. Estrogen and peptide YY are associated with bone mineral density in premenopausal exercising women. Bone 2011:49:194-201.

127 Marini JC. Do bisphosphonates make children's bones better or brittle? N Engl Med 2003:349:423-6.

128 Papapoulos SE, Cremers SC. Prolonged bisphosphonate release after treatment in children. N Eng/ J Med 2007:356:1075-6.

129 Canalis E. Update in new anabolic therapies for osteoporosis. J Clin Endocrinol Metab 2010:95:1496-504. 
130 Eriksen EF, Halse J, Moen MH. New developments in the treatment of osteoporosis. Acta Obstet Gynecol Scand 2013;92:620-36.

131 Grinspoon S, Thomas L, Miller K, et al. Effects of recombinant human IGF-I and oral contraceptive administration on bone density in anorexia nervosa. J Clin Endocrinol Metab 2002:87:2883-91.

132 Misra M, McGrane J, Miller KK, et al. Effects of rhIGF-1 administration on surrogate markers of bone turnover in adolescents with anorexia nervosa. Bone 2009:45:493-8.

133 Welt CK, Chan JL, Bullen J, et al. Recombinant human leptin in women with hypothalamic amenorrhea. N Engl J Med 2004;351:987-97.

134 Sienkiewicz E, Magkos F, Aronis KN, et al. Long-term metreleptin treatment increases bone mineral density and content at the lumbar spine of lean hypoleptinemic women. Metabolism 2011;60:1211-21.

135 Chou SH, Chamberland JP, Liu X, et al. Leptin is an effective treatment for hypothalamic amenorrhea. Proc Natl Acad Sci USA 2011;108:6585-90.

136 Sim I, Ebeling PR. Treatment of osteoporosis in men with bisphosphonates: rationale and latest evidence. Ther Adv Musculoskelet Dis 2013;5:259-67.
137 Ebeling PR. Osteoporosis in men. Curr Opin Rheumatol 2013;25:542-52.

138 Thompson RA, Sherman RT. Eating disorders in sport. New York: Routledge, 2010.

139 Mitchell JE, Roerig J, Steffen K. Biological therapies for eating disorders. Int J Eat Disord 2013;46:470-7.

140 Skårderud F, Fladvad T, Garthe I, et al. Den dårlig ernærte utøveren. Vektreduksjon, kroppsmodifikasjon og spiseforstyrrelser i toppidrett. Retningslinjer for holdning og handling. Oslo: Olympiatoppen, 2012. http://www. olympiatoppen. no/fagomraader/idrettsernaering/Fagstoff/page6827.html (accessed 4 June 2012).

141 Sutton L, Stewart AD. A professional discipline and inter-disciplinary toolkit. In: Stewart AD, Sutton L. eds Body composition in sport, exercise and health. Abingdon, UK: Routledge, 2012:187-208.

142 Jackson AS, Pollock ML. Practical assessment of body compositon. Phys Sports Med 1985;13:76-90.

143 Creighton DW, Shrier I, Shultz R, et al. Return-to-play in sport: a decision-based model. Clin J Sport Med 2010;20:379-85.

144 Matheson GO, Shultz R, Bido J, et al. Return-to-play decisions: are they the team physician's responsibility? Clin I Sport Med 2011;21:25-30. 